\title{
A randomized comparison of the Saphenous Vein Versus Right Internal Thoracic Artery as a Y-Composite Graft (SAVE RITA) trial: Early results
}

\author{
Ho Young Hwang, MD, PhD, ${ }^{a}$ Jun Sung Kim, MD, ${ }^{\mathrm{b}}$ Se Jin Oh, MD, ${ }^{a}$ and Ki-Bong Kim, MD, PhD ${ }^{\mathrm{a}}$
}

Objective: The Saphenous Vein Versus Right Internal Thoracic Artery as a Y-Composite Graft trial was designed to evaluate the saphenous vein compared with the right internal thoracic artery as a Y-composite graft anastomosed to the side of the left internal thoracic artery. In this early analysis, we compared early angiographic patency rates and clinical outcomes.

\begin{abstract}
Methods: From September 2008 to October 2011, 224 patients with multivessel coronary artery disease were randomized prospectively to undergo off-pump revascularization using the saphenous vein group $(\mathrm{n}=112)$ or the right internal thoracic artery group $(\mathrm{n}=112)$ as $\mathrm{Y}$-composite grafts. Early postoperative $(1.4 \pm 1.1$ days $)$ angiographic patency and clinical outcomes were compared.
\end{abstract}

Results: There was 1 operative death in the right internal thoracic artery group. No statistically significant differences in postoperative morbidities, including atrial fibrillation and acute renal failure, were observed between the groups. The number of distal anastomoses using the side-arm Y-composite graft (saphenous vein vs right internal thoracic artery) were $2.3 \pm 0.8$ and $1.9 \pm 0.7$ in the saphenous vein and right internal thoracic artery groups, respectively $(P<.001)$. A third conduit was used in 44 patients (saphenous vein group vs right internal thoracic artery group, $4 / 109$ vs $40 / 110 ; P<.001)$ to extend the side-arm Y-composite graft for complete revascularization. Early angiography demonstrated an overall patency rate of $99.4 \%$ (771 of 776 distal anastomoses). Patency rates of the side-arm Y-composite graft (saphenous vein vs right internal thoracic artery) were $98.8 \%$ ( 245 of 248 ) and $99.5 \%$ (207 of 208) in the saphenous vein and right internal thoracic artery groups, respectively $(P=.629)$.

Conclusions: A third conduit was needed to extend the right internal thoracic artery composite graft and reach the target vessels in $36.4 \%$ (40/110) of the patients. The saphenous vein composite graft was comparable with the right internal thoracic artery composite graft in terms of early angiographic patency and clinical outcomes. ( $J$ Thorac Cardiovasc Surg 2012;144:1027-35)

The saphenous vein (SV) has been one of the most widely used conduits for coronary artery bypass grafting (CABG) because of its advantages, such as easy accessibility, sufficient length, short harvest time, and ease of manipulation. However, there have been concerns about the suitability of the SV graft in CABG resulting from structural and functional differences between veins and arteries. ${ }^{1}$ Poor longterm patency rates and clinical outcomes have been reported after CABG performed with SV aortocoronary grafts compared with $\mathrm{CABG}$ performed with arterial

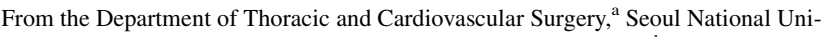
versity Hospital, Seoul National University Bundang Hospital, ${ }^{\mathrm{b}}$ Seoul National University College of Medicine, Seoul, Korea.

Disclosures: Authors have nothing to disclose with regard to commercial support

Read at the 92nd Annual Meeting of The American Association for Thoracic Surgery, San Francisco, California, April 28-May 2, 2012.

Received for publication April 25, 2012; revisions received July 8, 2012; accepted for publication July 26, 2012; available ahead of print Aug 30, 2012.

Address for reprints: Ki-Bong Kim, MD, PhD, Department of Thoracic and Cardiovascular Surgery, Seoul National University Hospital, 101 Daehak-ro, Jongno-gu, Seoul 110-744, Korea (E-mail: kimkb@snu.ac.kr).

$0022-5223 / \$ 36.00$

Copyright (c) 2012 by The American Association for Thoracic Surgery

http://dx.doi.org/10.1016/j.jtcvs.2012.07.054
}

grafts. ${ }^{2-4}$ Of the various arterial grafts used in myocardial revascularization, the right internal thoracic artery (ITA) has been considered a second conduit of choice after the left ITA. ${ }^{5,6}$ In our previous studies, we demonstrated the merits of right ITA composite grafts in terms of angiographic patency and clinical results. ${ }^{7-9}$

In another previous study by our group, the SV composite graft showed a similar patency rate compared with the arterial composite graft 1 year after surgery. ${ }^{10}$ The theoretical advantages of using the SV as a composite graft based on the in situ left ITA include less exposure to direct pressure and circulatory stress from the ascending aorta and continuous exposure to nitric oxide released from the in situ left ITA. ${ }^{11,12}$ However, few studies using the SV as a composite graft have been conducted. ${ }^{10,13,14}$ The Saphenous Vein Versus Right Internal Thoracic Artery as a Y-Composite Graft (SAVE RITA) trial is a randomized, controlled clinical trial designed to evaluate the SV compared with the right ITA as a Y-composite graft based on the in situ left ITA in terms of 1-year angiographic patency rates and mid-term clinical outcomes. As an early analysis, we compared early angiographic patency rates 


\section{Abbreviations and Acronyms \\ CABG = coronary artery bypass grafting \\ ITA $=$ internal thoracic artery \\ $\mathrm{OPCAB}=$ off-pump coronary artery bypass grafting \\ RITA $=$ right internal thoracic artery Y-composite graft \\ SAVE RITA $=$ Saphenous Vein Versus Right Internal Thoracic Artery as a Y-Composite Graft trial \\ SV $\quad=$ saphenous vein \\ SVG $\quad=$ saphenous vein Y-composite graft}

and clinical outcomes of CABG using the SV as a Y-composite graft with those of CABG using the right ITA as a composite graft.

\section{MATERIALS AND METHODS}

The study protocol was approved by the institutional review board (approval no. H-0803-024-237), and informed consent was obtained from all study patients.

\section{Study Design}

The study was designed according to the Consolidated Standards of Reporting Trials statement. ${ }^{15}$ Patients, 40 to 75 years of age, who were scheduled to undergo off-pump CABG (OPCAB) for multivessel coronary artery disease on a nonemergency basis and who were expected to receive a Y-composite graft based on the in situ left ITA were eligible for the study if they had an estimated left ventricular ejection fraction $>25 \%$. Exclusion criteria included patients with ineligible Y-composite graft revascularization, unavailable right ITA or SV, chronic renal failure requiring renal replacement therapy that might prohibit early and 1-year coronary angiographic evaluation, a history of previous cardiac operation, and a medical history such as malignant disease that might limit the possibility of midterm follow-up. Patients with an estimated left ventricular ejection fraction $\leq 25 \%$ were also excluded because of the possibility of on-pump conversion during $\mathrm{OPCAB}$ and the possibility of a need for additional conduit in a dilated left ventricle.

Of 511 patients who underwent isolated CABG at our institution between September 2008 and October 2011, patients who were scheduled to undergo OPCAB $(n=496)$ were assessed for eligibility. Eligible patients who were expected to receive an in situ left ITA-based Y-composite graft for complete revascularization $(n=224)$ based on the side-arm conduit used for construction of a Y-composite graft were assigned randomly to 1 of the 2 operative strategies in a 1:1 manner: The SV Y-composite graft (the SVG group, $\mathrm{n}=112$ ) or the free right ITA Y-composite graft (the RITA group, $n=112$; Figure 1). After the pericardium was opened and the coronary arterial anatomies were assessed for availability for revascularization using a Y-composite graft, randomization was performed with a web-based block randomization method with randomly determined block sizes of 4 and 6 . After intraoperative randomization, operative strategies were changed in 5 patients: on-pump CABG conversion was performed in 1 patient because of hemodynamic instability, and grafting strategies were changed in 4 patients because of unsuitable condition of the conduits or coronary arteries (damaged ITA during harvesting in 2 patients, small size and poor quality of the SV in 1 patient, and constrictive pericarditis with invisible target coronary arteries in 1 patient). Mean age at the time of operation was $62.7 \pm 7.8$ years. There were no statistically significant differences in demographic data and preoperative risk factors between the 2 groups (Table 1).

\section{Operative Strategies}

Basic surgical procedures and principles of $\mathrm{OPCAB}$ and harvesting technique of the SV have been described previously.,10,16 Our surgical strategies during the study period were performing off-pump revascularization using a composite graft based on the left ITA and avoiding aortic manipulation in most patients. Both the left and right ITAs were harvested using a skeletonization technique. The proximal dissection of the ITA was carried to the inferior border of the subclavian vein and the ITA was divided distally just proximal to the bifurcation. The greater SV from a lower leg was chosen for use in grafting as opposed to the upper leg SV to decrease the possibility of size mismatch with native coronary arteries or ITA. SV harvest was initiated after systemic heparinization during harvest of the left ITA and was performed using an atraumatic, open technique. Proximal dissection of the SV was carried to approximately $3 \mathrm{~cm}$ below the knee and the SV was divided distally approximately $5 \mathrm{~cm}$ proximal to the ankle. Tension on the SV was minimized during harvest, and manual intraluminal dilatation was avoided.

Immediately after the side-arm conduit (SV or right ITA) was harvested, it was anastomosed to the side of the left ITA without any pharmacologic treatment to construct a Y-composite graft. We always performed the Y anastomosis first, before constructing distal anastomoses, because it was possible to perfuse ischemic myocardium after each distal anastomosis during OPCAB. After the Y-composite graft was constructed, in almost all the patients the left anterior descending coronary artery territory was revascularized first by using the left ITA while the distal end of the side-arm conduit was clamped with an atraumatic bulldog clamp and left to be dilated spontaneously by the native flow and pressure of the left ITA. The left circumflex coronary artery territory was then revascularized, followed by the right coronary artery territory.

A sequential anastomotic technique using each side arm of the Y-composite graft was almost always used for complete revascularization when more than 2 coronary arterial anastomoses were needed. When constructing a sequential anastomosis, longitudinal, perpendicular, or oblique sequential side-to-side anastomosis was performed to permit efficient use of conduit.

When the length of one or both arms of the Y graft was not sufficient to reach the target vessels, an additional SV segment from the other lower leg was harvested to lengthen the graft arm in an I-shape. Patients were given an initial dose of heparin $(1.5 \mathrm{mg} / \mathrm{kg})$ and periodic supplemental doses to maintain an activated clotting time of $>300$ seconds. All patients took aspirin until the day of surgery and resumed it as soon as possible after surgery, usually 1 day postoperatively. If the patient had a high blood level of low-density lipoprotein cholesterol (>100 mg/dL) postoperatively, drug therapy was initiated.

\section{Angiographic Evaluation of Graft Patency}

Early postoperative ( $1.4 \pm 1.1$ days) angiography for evaluation of the anastomotic sites and patency of the grafts was performed in all the study patients except the 1 operative death. Informed written consent, including the possible benefits and risks of postoperative angiography, was obtained from all patients. One physician initially reviewed all coronary angiograms, and consensus was reached after review. Graft patency was graded in the manner described by FitzGibbon, Burton, and Leach ${ }^{17}$ (grade A, excellent; grade B, fair). Grades A and B were treated as patent. Grade O anastomosis, which included stenosis of $75 \%$ or more of vessel diameter or a totally occluded graft, was treated as occluded.

\section{Evaluation of Early Clinical Outcomes}

Operative mortality was defined as any death within 30 days, including deaths after hospital discharge. The patients were monitored continuously 


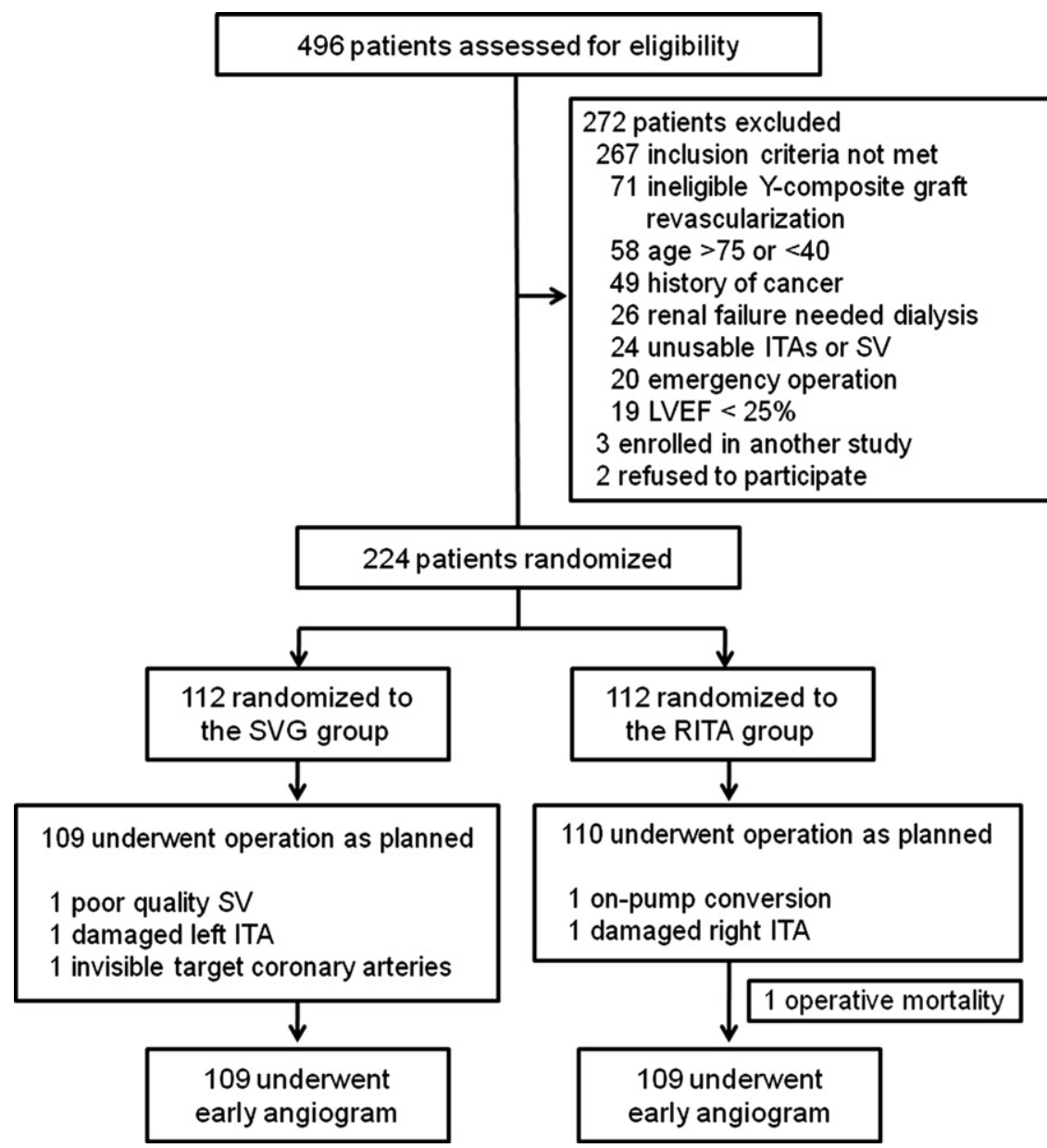

FIGURE 1. Summary flow diagram of participants. ITA, Internal thoracic artery; $S V$, saphenous vein; $L V E F$, left ventricular ejection fraction; $S V G$, saphenous vein Y-composite graft; RITA, right internal thoracic artery Y-composite graft.

with postoperative electrocardiography during stays in the intensive care unit and in the general ward until chest tube removal. A standard 12-lead electrocardiogram was checked daily thereafter during the hospital stay. Occurrence of any short runs of atrial fibrillation during the hospital stay was considered to represent development of atrial fibrillation. Respiratory complications included postoperative pneumonia or $>48$ hours of prolonged ventilator support. Perioperative myocardial infarction was defined as positive results on at least 2 of 3 different tests—elevated peak serum

TABLE 1. Preoperative characteristics and risk factors of the study patients

\begin{tabular}{|c|c|c|c|c|}
\hline Variables & Total $(n=224)$ & SVG group $(n=112)$ & RITA group $(n=112)$ & $P$ value \\
\hline Age, y & $63.0 \pm 7.9$ & $63.3 \pm 7.8$ & $62.8 \pm 8.0$ & .647 \\
\hline Female, $\mathrm{n}(\%)$ & $51(22.8)$ & $30(26.8)$ & $21(18.8)$ & .152 \\
\hline \multicolumn{5}{|l|}{ Risk factors, $\mathrm{n}(\%)$} \\
\hline Smoking & $110(49.1)$ & $57(50.9)$ & $53(47.3)$ & .593 \\
\hline Hypertension & $156(69.6)$ & $80(71.4)$ & $76(67.9)$ & .561 \\
\hline Diabetes mellitus & $98(43.8)$ & $47(42.0)$ & $51(45.5)$ & .590 \\
\hline Dyslipidemia & $33(14.7)$ & $19(17.0)$ & $14(12.5)$ & .346 \\
\hline Overweight (BMI $\geq 25 \mathrm{~kg} / \mathrm{m}^{2}$ ) & $102(45.5)$ & $51(45.5)$ & $51(45.5)$ & $>.999$ \\
\hline History of stroke & $31(13.8)$ & $13(11.6)$ & $18(16.1)$ & .333 \\
\hline Unstable angina & $167(74.6)$ & $83(74.1)$ & $84(75.0)$ & .878 \\
\hline Left main disease & $84(37.5)$ & $41(36.6)$ & $43(38.4)$ & .783 \\
\hline Three-vessel disease & $177(79.0)$ & $90(80.4)$ & $87(77.7)$ & .623 \\
\hline Logistic EuroSCORE, \% & $3.2 \pm 2.5$ & $3.2 \pm 2.5$ & $3.3 \pm 2.7$ & .710 \\
\hline LVEF, \% & $57.1 \pm 9.6$ & $58.0 \pm 9.7$ & $56.2 \pm 9.2$ & .172 \\
\hline
\end{tabular}

SVG, Saphenous vein Y-composite graft; RITA, right internal thoracic artery Y-composite graft; $B M I$, body mass index; $L V E F$, left ventricular ejection fraction. 
creatine kinase isoenzyme level ( $>100 \mathrm{ng} / \mathrm{mL})$, appearance of new Q waves on the electrocardiogram, or newly developed regional wall motion abnormalities on the postoperative echocardiogram. Postoperative acute renal failure was defined as an increase of $>50 \%$ in serum creatinine level from the preoperative value or a need for renal replacement therapy regardless of serum creatinine level. Low cardiac output syndrome was defined as a cardiac index $<2.0 \mathrm{~L} / \mathrm{min}$ per square meter or a systolic arterial pressure $<90 \mathrm{~mm} \mathrm{Hg}$ requiring inotropic support (dopamine or dobutamine) of $>5 \mu \mathrm{g} / \mathrm{kg}$ per minute.

\section{End Points}

The primary end point of the SAVE RITA trial was the 1-year angiographic patency rate of the distal anastomoses performed with a side-arm composite graft (SV or right ITA). Secondary end points were early postoperative angiographic patency rates and mid-term clinical outcomes, including overall survival, freedom from cardiac death, and freedom from major adverse cardiac and cerebrovascular events (defined as cardiac death including sudden death during follow-up, acute myocardial infarction, reintervention including redo-CABG, and cerebrovascular accident).

\section{Statistical Analysis}

The study was designed to have $80 \%$ power to detect 1-year patency rates of $93 \%$ in the SV versus $95 \%$ in the right ITA grafts, with a 1 -sided type I error of $5 \%$ and a noninferiority margin of $-8 \%$. A total of 194 anastomoses were required in each group. Using an estimated average number of 2 distal anastomoses per conduit, 97 patients were needed to complete the study cohort. Allowing for a 3\% dropout during the perioperative period and $10 \%$ dropout during the 1-year follow-up, we determined that recruitment of 112 patients in each group was necessary.

Statistical analysis was performed with the SPSS software package (version 12.0; SPSS Inc, Chicago, Ill). Data were expressed as mean \pm standard deviation, or proportions. Comparisons between the 2 groups were made using the $\chi^{2}$ test and Fisher exact test for categorical variables and the Student $t$-test for continuous variables. A $P$ value of $<.05$ was considered as statistically significant. All preoperative and postoperative variables were compared with an intention-to-treat base. However, numbers of distal anastomoses and patency rates were compared after excluding 5 patients in whom the revascularization strategy was changed by intraoperative events.

\section{RESULTS \\ Operative Data}

The average length of the harvested skeletonized right ITA was $14.9 \pm 1.5 \mathrm{~cm}$ (range, $11-19 \mathrm{~cm}$ ) and was shorter than the average length of the greater SV harvested from a lower leg $(16.9 \pm 2.1 \mathrm{~cm}$; range, $12-21 \mathrm{~cm} ; P<.001)$. The average number of distal anastomoses per patient (SVG vs RITA groups; $3.54 \pm 0.86$ vs $3.57 \pm 0.76$, $P=.769)$ and the average number of distal anastomoses using the left ITA (SVG vs RITA groups; $1.24 \pm 0.45$ vs 1.20 $\pm 0.49, P=.585$ ) were similar between the 2 groups. However, the number of distal anastomoses using the side-arm composite graft (SV or right ITA) was larger in the SVG group than in the RITA group (SVG vs RITA groups; 2.28 \pm 0.79 vs $1.91 \pm 0.67, P<.001$; Table 2 ).

When the length of 1 or both arms of the Y graft was not sufficient for complete revascularization, an additional SV segment from a lower leg (a third conduit) was harvested to lengthen the conduit in an I-shape. A third SV conduit was needed in 46 patients (SVG vs RITA groups; 4 vs 42 ,
TABLE 2. Comparison of the number of distal anastomoses between the SVG and RITA groups

\begin{tabular}{lcccr}
\hline Variables & $\begin{array}{c}\text { Total } \\
(\mathbf{n}=\mathbf{2 1 9})\end{array}$ & $\begin{array}{c}\text { SVG group } \\
(\mathbf{n}=\mathbf{1 0 9})\end{array}$ & $\begin{array}{c}\text { RITA group } \\
(\mathbf{n}=\mathbf{1 1 0})\end{array}$ & $\begin{array}{c}\boldsymbol{P} \\
\text { value }\end{array}$ \\
\hline $\begin{array}{c}\text { No. of distal } \\
\text { anastomoses }\end{array}$ & & & & \\
Per patient & $3.56 \pm 0.81$ & $3.54 \pm 0.86$ & $3.57 \pm 0.76$ & .769 \\
Per the left ITA & $1.22 \pm 0.47$ & $1.24 \pm 0.45$ & $1.20 \pm 0.49$ & .585 \\
$\begin{array}{c}\text { Per the second } \\
\text { conduit }\end{array}$ & $2.10 \pm 0.75$ & $2.28 \pm 0.79$ & $1.91 \pm 0.67$ & $<.001$ \\
\hline
\end{tabular}

$\overline{S V G}$, Saphenous vein Y-composite graft; RITA, right internal thoracic artery Y-composite graft; ITA, internal thoracic artery.

$P<.001)$. In the SVG group, an additional SV segment was harvested from the other lower leg to lengthen the SV composite graft $(\mathrm{n}=4$; average length, $3.8 \pm 0.5 \mathrm{~cm})$. In the RITA group, the SV was harvested as a third conduit in 42 patients (average length, $5.8 \pm 2.8 \mathrm{~cm}$ ) and connected to the left $(\mathrm{n}=2)$ or right $(\mathrm{n}=40)$ ITA to reach the target vessels. Of 87 patients in the RITA group who had 3-vessel disease, 40 patients $(46.0 \%)$ needed an additional SV segment for complete revascularization of all coronary artery territories. A sequential anastomotic technique was used in 204 patients $(91 \%)$ without intergroup difference (SVG vs RITA groups; 101 patients vs 103 patients, $P=.639$ ). The number of distal anastomoses in the 3 coronary artery territories was also similar between the 2 groups (Table 3 ).

\section{Early Clinical Outcomes}

In-hospital mortality was $0 \%$ in the SVG group and $0.9 \%$ (1 of 112 patients) in the RITA group $(P>.999)$. Median duration of mechanical ventilation and intensive care unit stay were 16 hours (range, 5-168 hours) and 22 hours (range, 12-284 hours), respectively. There were no differences in ventilation and intensive care unit stay times between the 2 groups ( $P=.773$ and $P=.308$, respectively). Postoperative complications included atrial fibrillation $(\mathrm{n}=33,14.7 \%)$, respiratory complications $(\mathrm{n}=7$, $3.1 \%)$, acute renal failure $(\mathrm{n}=4,1.8 \%)$, reoperation for bleeding $(\mathrm{n}=3,1.3 \%)$, perioperative myocardial infarction $(\mathrm{n}=1,0.4 \%)$, and mediastinitis $(\mathrm{n}=1,0.4 \%)$. None of the patients experienced cerebrovascular accident. No statistically significant differences in early clinical outcomes

TABLE 3. Number of distal anastomoses according to the coronary artery territories

\begin{tabular}{lcccc}
\hline \multicolumn{1}{c}{ Variables } & $\begin{array}{c}\text { Total } \\
(\mathbf{n}=\mathbf{2 1 9})\end{array}$ & $\begin{array}{c}\text { SVG group } \\
(\mathbf{n}=\mathbf{1 0 9})\end{array}$ & $\begin{array}{c}\text { RITA group } \\
(\mathbf{n}=\mathbf{1 1 0})\end{array}$ & $\begin{array}{c}\boldsymbol{P} \\
\text { value }\end{array}$ \\
\hline Total & $3.56 \pm 0.81$ & $3.54 \pm 0.86$ & $3.57 \pm 0.76$ & .769 \\
LAD territory & $1.65 \pm 0.56$ & $1.66 \pm 0.58$ & $1.62 \pm 0.56$ & .605 \\
LCX territory & $1.15 \pm 0.49$ & $1.14 \pm 0.50$ & $1.17 \pm 0.48$ & .664 \\
RCA territory & $0.76 \pm 0.57$ & $0.75 \pm 0.60$ & $0.78 \pm 0.52$ & .649 \\
\hline
\end{tabular}

$S V G$, Saphenous vein Y-composite graft; RITA, right internal thoracic artery Y-composite graft; $L A D$, left anterior descending coronary artery; $L C X$, left circumflex coronary artery; $R C A$, right coronary artery. 
TABLE 4. Comparison of early clinical results

\begin{tabular}{|c|c|c|c|c|}
\hline Variables & Total $(n=224)$ & SVG group $(n=112)$ & RITA group $(n=112)$ & $P$ value \\
\hline In-hospital mortality, n (\%) & $1(0.4)$ & $0(0)$ & $1(0.9)$ & $>.999$ \\
\hline \multicolumn{5}{|l|}{ Postoperative morbidity, n (\%) } \\
\hline Atrial fibrillation & $33(14.7)$ & $12(10.7)$ & $21(18.8)$ & .090 \\
\hline Respiratory complication & $7(3.1)$ & $4(3.6)$ & $3(2.7)$ & $>.999$ \\
\hline Acute renal failure & $4(1.8)$ & $1(0.9)$ & $3(2.7)$ & .622 \\
\hline Reoperation for bleeding & $3(1.3)$ & $2(1.8)$ & $1(0.9)$ & $>.999$ \\
\hline Perioperative MI & $1(0.4)$ & $1(0.9)$ & $0(0)$ & $>.999$ \\
\hline Mediastinitis & $1(0.4)$ & $1(0.9)$ & $0(0)$ & $>.999$ \\
\hline Low cardiac output syndrome & $1(0.4)$ & $0(0)$ & $1(0.9)$ & $>.999$ \\
\hline
\end{tabular}

SVG, Saphenous vein Y-composite graft; RITA, right internal thoracic artery Y-composite graft; $M I$, myocardial infarction.

were observed between the 2 groups (Table 4). In the SVG group, 2 patients experienced delayed healing of the lower leg wound. The hospital stay durations were $7.9 \pm 3.1$ days in the SVG group and $7.2 \pm 2.9$ days in the RITA group $(P=.076)$.

\section{Early Angiographic Results}

Early postoperative angiography demonstrated overall patency rates of $99.0 \%$ (383 of 387 anastomoses) and $99.7 \%$ (388 of 389) in the SVG and RITA groups, respectively $(P=.216)$. Patency rate for distal anastomoses using the left ITA was $100 \%$ (266 of 266). The patency rate of the SV side-arm composite graft in the SV group was $98.8 \%$ (245 of 248), and was not significantly different from the patency rate of the right ITA composite graft in the RITA group $(99.5 \%, 207$ of 208; $P=.629$; Table 5$)$. When the side-arm composite graft patency rates were compared based on the target coronary artery territories, SV graft patency rates were similar to those of the right ITA (Table 6). During the study period, we did not find any composite graft with stenosis $\geq 50 \%$ at the Y-anastomosis site.

\section{DISCUSSION}

The current study revealed 2 main findings. First, early angiographic patency rates and clinical outcomes of $\mathrm{OPCAB}$ using the $\mathrm{SV}$ as a side-arm Y-composite graft based on the in situ left ITA were similar to those of OPCAB using a right ITA composite graft. Second, a third conduit was needed to extend the right ITA composite graft and reach the target vessels in $36.4 \%$ (40 of 110 patients) of the RITA group patients.

The SAVE RITA trial was designed to evaluate the SV compared with the right ITA as a side-arm Y-composite graft in terms of early and 1-year angiographic patency rates and mid-term clinical outcomes. The study design had a 3\% expected dropout rate, and 5 of 224 randomized patients ( $2.2 \%$; SVG vs RITA groups, 3 patients vs 2 patients) did not undergo their planned operation because of intraoperative events and were excluded during the perioperative period. Preoperative characteristics and risk factors including logistic EuroSCORE were well matched between the 2 groups. All the study patients except 1 operative death (109 patients in each group) underwent early postoperative $(\leq 7$ days) angiography.

Poor long-term patency rates and clinical outcomes have been reported after CABG performed using SV grafts compared with those after CABG performed with arterial grafts such as the ITAs and right gastroepiploic artery. ${ }^{2-4}$ The right ITA has been considered a second graft of choice because of its freedom from atherosclerotic changes, excellent long-term patency, and improved long-term survival rates. ${ }^{5,6}$ Merits of right ITA composite grafts have also been well demonstrated in terms of angiographic patency and clinical results. ${ }^{7-9,18} \mathrm{SV}$ graft patency is influenced by 3 processes: Thrombosis, fibrointimal hyperplasia, and atherosclerosis. ${ }^{19}$ Various efforts to preserve structure and function of the venous endothelium, including technical modifications of SV harvesting, pharmacologic treatment, and genetic engineering, have been made to overcome limitations of SV grafts. ${ }^{20-22}$ In addition, the SV must tolerate the pressure and circulatory stress of ascending aortic pressure and flow when it is used as an aortocoronary bypass graft. ${ }^{11,12}$ However, few studies have reported results of CABG using the SV as a composite graft. ${ }^{10,13,14}$ Theoretical advantages of using the SV as a side-arm composite graft over an aortocoronary bypass graft are (1) the

TABLE 5. Early angiographic patency rates for distal anastomoses

\begin{tabular}{|c|c|c|c|c|}
\hline Variables & Total $(\mathbf{n}=\mathbf{2 1 8})$ & SVG group $(n=109)$ & RITA group $(\mathbf{n}=109)$ & $P$ value \\
\hline Overall grafts & $771 / 776(99.4 \%)$ & $383 / 387(99.0 \%)$ & $388 / 389(99.7 \%)$ & .216 \\
\hline Grafts using left ITA & $266 / 266(100 \%)$ & $135 / 135(100 \%)$ & $131 / 131(100 \%)$ & - \\
\hline Grafts using second conduit & $452 / 456(99.1 \%)$ & $245 / 248(98.8 \%)$ & $207 / 208(99.5 \%)$ & .629 \\
\hline Grafts using third conduit & $53 / 54(98.1 \%)$ & $3 / 4(75.0 \%)$ & $50 / 50(100 \%)$ & .074 \\
\hline
\end{tabular}

SVG, Saphenous vein Y-composite graft; RITA, right internal thoracic artery Y-composite graft; ITA, internal thoracic artery. 
TABLE 6. Comparison of patency rates for distal anastomoses performed with second conduits between the saphenous veins and right internal thoracic arteries based on coronary territories

\begin{tabular}{lccr}
\hline & $\begin{array}{c}\text { SVG group } \\
(\mathbf{n}=\mathbf{1 0 9})\end{array}$ & $\begin{array}{c}\text { RITA group } \\
(\mathbf{n}=\mathbf{1 0 9})\end{array}$ & $\begin{array}{c}\boldsymbol{P} \\
\text { value }\end{array}$ \\
\hline Total & $245 / 248(98.8 \%)$ & $207 / 208(99.5 \%)$ & .629 \\
LAD territory & $47 / 47(100 \%)$ & $42 / 43(97.7 \%)$ & .478 \\
LCX territory & $123 / 124(99.2 \%)$ & $121 / 121(100 \%)$ & $>.999$ \\
RCA territory & $75 / 77(97.4 \%)$ & $44 / 44(100 \%)$ & .533 \\
\hline
\end{tabular}

SVG, Saphenous vein Y-composite graft; RITA, right internal thoracic artery Y-composite graft; $L A D$, left anterior descending coronary artery; $L C X$, left circumflex coronary artery; $R C A$, right coronary artery.

SV conduit anastomosed to the side of the left ITA is exposed to less pressure and circulatory stress than a conduit anastomosed to the ascending aorta and (2) the SV composite graft is exposed continuously to nitric oxide produced from the left ITA, which may reduce the risk of atherosclerotic disease. ${ }^{11,12}$ In a previous study performed by our group ${ }^{16}$ adoption of a minimal manipulation technique for SV harvest and using the SV as a composite graft were demonstrated to be beneficial in preserving venous endothelial structure and function.

Previous studies reported that early (1 day to 2 months) patency rates of the SV grafts harvested with a conventional method and used as a aortocoronary bypass were also lower than patency rates of arterial grafts, with patency rates ranging from $85.2 \%$ to $93.5 \%{ }^{4,23,24}$ In the current study, we analyzed early angiographic patency rates and clinical outcomes of OPCAB using SV composite grafts and compared them with those of OPCAB using right ITA composite grafts. The intention-to-treat analysis revealed that early clinical outcomes including in-hospital mortality and postoperative complications were similar between the 2 groups. Early postoperative angiography demonstrated that the patency rates of distal anastomoses using SV composite grafts were comparable with distal anastomoses performed using right ITA composite grafts. The patency rates of the target coronary territories also were similar between the 2 groups. Because the SV composite graft patency rate $(98.8 \%)$ in the current study was higher than the SV aortocoronary bypass graft patency rate $(86.4 \%)$ in our previous retrospective study, we expect the SV composite graft patency rate to be comparable with that of the right ITA composite graft at 1 year. ${ }^{4,25}$

Although construction of a composite graft allows the extensive use of bilateral skeletonized ITA grafts to revascularize both the left and right coronary systems, ${ }^{7,9}$ the length of the right ITA is still a limitation for complete revascularization, particularly in patients with cardiomegaly. In the current study, the average length of the harvested skeletonized right ITA was $14.9 \pm 1.5 \mathrm{~cm}$, and $46 \%$ of patients with 3 -vessel disease in the RITA group needed an additional conduit to perform complete revascularization. This was in agreement with a previous study demonstrating that two thirds of distal anastomoses on the right coronary artery territory were performed using a third graft in patients with 3-vessel disease who underwent CABG using bilateral ITA Y-composite grafts. ${ }^{18}$

\section{Study Limitations}

There are limitations to the current study that must be recognized. First, the current study is not a multicenter "all-comers" study, although it is a prospective, randomized, controlled trial. Construction of Y-composite grafts can be a technically demanding procedure, which may limit the possibility of generalizing our results to a large surgical population. Patients from our institution may differ from those treated elsewhere. The study should be performed as a multicenter-based trial to overcome the institutional factor. Second, early graft patency rates and clinical outcomes do not provide sufficient data to reach a conclusion on the suitability of the SV composite graft. The SAVE RITA trial has completed patient enrollment and we are now following up with patients for their 1-year angiographies and mid-term clinical outcomes. In addition, it will be necessary to extend our patency study up to several years after surgery to demonstrate that the advantages of SV composite grafting are sufficient to overcome the previously published advantages of the right ITA over the SV as an additional conduit.

\section{References}

1. Cox JL, Chiasson DA, Gotlieb AI. Stranger in a strange land: the pathogenesis of saphenous vein graft stenosis with emphasis on structural and functional differences between veins and arteries. Prog Cardiovasc Dis. 1991; 34:45-68.

2. Cameron A, Davis KB, Green G, Schaff HV. Coronary bypass surgery with internal-thoracic-artery grafts: effects on survival over a 15-year period. N Engl J Med. 1996;334:216-20.

3. Cho KR, Kim J-S, Choi J-S, Kim K-B. Serial angiographic follow-up of grafts one year and five years after coronary artery bypass surgery. Eur J Cardiothorac Surg. 2006;29:511-6.

4. Kim K-B, Cho KR, Jeong DS. Midterm angiographic follow-up after offpump coronary artery bypass: serial comparison using early, 1-year, and 5-year postoperative angiograms. J Thorac Cardiovasc Surg. 2008;135: $300-7$

5. Lytle BW, Blackstone EH, Loop FD, Houghtaling PL, Arnold JM, Akhrass R, et al. Two internal thoracic artery grafts are better than one. J Thorac Cardiovasc Surg. 1999; 117:855-72.

6. Buxton BF, Komeda M, Fuller JA, Gordon I. Bilateral internal thoracic artery grafting may improve outcome of coronary artery surgery: risk adjusted survival. Circulation. 1998;98:II1-6.

7. Kim K-B, Cho KR, Chang WI, Lim C, Ham BM, Kim YL. Bilateral skeletonized internal thoracic artery graftings in off-pump coronary artery bypass: early result of Y versus in situ grafts. Ann Thorac Surg. 2002;74:S1371-6.

8. Cho KR, Hwang HY, Kang WJ, Lee DS, Kim KB. Progressive improvement of myocardial perfusion after off-pump revascularization with bilateral internal thoracic arteries: comparison of early versus 1-year postoperative myocardial single photon emission computed tomography. J Thorac Cardiovasc Surg. 2007;133: 52-7.

9. Hwang HY, Kim JS, Cho KR, Kim K-B. Bilateral internal thoracic artery in situ versus Y-composite graftings: five-year angiographic patency and long-term clinical outcomes. Ann Thorac Surg. 2011;92:579-85. 
10. Hwang HY, Kim JS, Kim K-B. Angiographic equivalency of off-pump saphenous vein and arterial composite grafts at one year. Ann Thorac Surg. 2010;90:516-21.

11. Filho JG, Leitão MC, Forte AJ, Filho HG, Silva AA, Bastos ES, et al. Flow analysis of left internal thoracic artery in myocardial revascularization surgery using Y graft. Tex Heart Inst J. 2006;44:430-6.

12. Tedoriya T, Kawasuji M, Sakakibara N, Ueyama K, Watanabe Y. Pressure characteristics in arterial grafts for coronary bypass surgery. Cardiovasc Surg. 1995; 3:381-5.

13. Gaudino M, Alessandrini F, Pragliola C, Luciani N, Trani C, Burzotta F, et al. Composite $\mathrm{Y}$ internal thoracic artery-saphenous vein grafts: short-term angiographic results and vasoreactive profile. J Thorac Cardiovasc Surg. 2004;127: 1139-44.

14. Bittner HB, Savitt MA, Ching PV, Ward HB. Off-pump coronary artery revascularization: ideal indication for patients with porcelain aorta and calcification of great vessels. J Cardiovasc Surg. 2003;44:217-21.

15. Rennie D. How to report randomized controlled trials: the CONSORT statement. JAMA. 1996;276:649.

16. Hwang HY, Kim M-A, Seo JW, Kim K-B. Endothelial preservation of the minimally manipulated saphenous vein composite graft: histologic and immunochemical study. J Thorac Cardiovasc Surg. 2012;144:190-6.

17. FitzGibbon GM, Burton JR, Leach AJ. Coronary bypass graft fate: angiographic grading of 1400 consecutive grafts early after operation and of 1132 after one year. Circulation. 1978;57:1070-4.

18. Glineur D, Hanet C, Poncelet A, D'hoore W, Funken JC, Rubay J, et al. Comparison of bilateral internal thoracic artery revascularization using in situ or Y graft configurations: a prospective randomized clinical, functional, and angiographic midterm evaluation. Circulation. 2008;118:S216-21.

19. FitzGibbon GM, Leach AJ, Kafka HP, Keon WJ. Coronary bypass graft fate: angiographic grading of 1400 consecutive grafts early after operation and of 1132 after one year. J Am Coll Cardiol. 1991;17:1075-80.

20. Wan S, Shukla N, Angelini GD, Yim APC, Johnson JL, Jeremy JY. Nitric oxide-donating aspirin (NCX 4016) inhibits neointimal thickening in a pig model of saphenous vein-carotid artery interposition grafting: a comparison with aspirin and morpholinosydnonimine (SIN-1). J Thorac Cardiovasc Surg. 2007;134:1033-9.

21. PREVENT IV investigators. Efficacy and safety of endifoligide an E2F transcription factor decoy, for prevention of vein graft failure following coronary artery bypass graft surgery: PREVENT IV: a randomized controlled trial. JAMA. 2005;294:2446-54.

22. Souza DSR, Johansson B, Bojö L, Karlsson R, Geijer H, Filbey D, et al. Harvesting the saphenous vein with surrounding tissue for $\mathrm{CABG}$ provides long-term graft patency comparable to the left internal thoracic artery: results of a randomized longitudinal trial. J Thorac Cardiovasc Surg. 2006;132:373-8.

23. Karski J, Djaiani G, Carroll J, Iwanochko M, Seneviratne P, Liu P, et al. Tranexamic acid and early saphenous vein graft patency in conventional coronary artery bypass graft surgery: a prospective randomized controlled clinical trial. J Thorac Cardiovasc Surg. 2005;130:309-14.

24. Goldman S, Copeland J, Moritz T, Henderson W, Zadina K, Ovitt T, et al. Improvement in early saphenous vein graft patency after coronary artery bypass surgery with antiplatelet therapy: results of a Veterans Administration Cooperative Study. Circulation. 1988;77:1324-32.

25. Cho KR, Jeong DS, Kim K-B. Influence of vein graft use on postoperative 1-year results after off-pump coronary artery bypass surgery. Eur J Cardiothorac Surg. 2007;32:718-23.

\section{Discussion}

Dr Brian F. Buxton (Richmond, Victoria, Australia). Thank you, Mr. Chairman. I would like to commence by thanking Dr Hwang for sending me the full paper last week.

Fundamentally, this is a very important randomized, controlled trial and has the potential of being one of the major trials comparing the saphenous vein with an arterial graft. So far as I am aware, there has been no other similar trial. The study was performed in the setting of a left internal thoracic Y-graft configuration. The coronary bypass procedure was performed off-pump by an experienced group of coronary artery bypass surgeons in patients with isolated coronary artery disease. The primary end points, as you saw, were graft patency and major clinical events at 1 year. The initial angiographic assessment was performed in the week after operation. Stenosis $>75 \%$ and occlusion were defined as occlusion.

The paper is well written. The relative graft patencies were determined using a noninferiority statistical model with a difference of $-8 \%$ between the saphenous vein and the right internal thoracic artery.

Mr. Chairman, before I go any further, I would like to make one comment. If we are to improve our techniques with randomized, controlled trials, what we need to do is have both an end point with functional and anatomic definitions. For example, fractional flow reserve is a way we can quantify the impact of the collateral circulation on study grafts, and the results should be incorporated in the composite end point. Assessing the collateral circulation by estimating the degree of stenosis alone in the native circulation is unreliable, particularly in the range between $50 \%$ and $90 \%$.

The authors have indicated that the sample size of 106 patients in each arm factored in the appropriate power calculation and sample size, and has allowed for patient dropouts. The term "interim analysis" is better avoided, and I think should be described as the early analysis. I disagree with the conclusion in the abstract that it was shown that noninferiority was not established, because this was not powered for in the early or interim analysis, but only for the results at 1 year. The authors have correctly withdrawn that statement from their presentation.

I have 3 questions that I would like to ask separately. First of all, there are 5 current, randomized, controlled trials looking at the patency of arterial and saphenous vein grafts. Each of these trials has a different definition of graft patency, making interpretation and meta-analysis very difficult. Could the authors clarify the definition? For example, is a graft with a stenosis of $80 \%$ patent or is it occluded?

Dr Hwang. Thank you for your nice comments. As you indicated, first of all, we omitted the term "noninferiority" in the presentation slides this afternoon and in the final submitted manuscript. Our statistician also advised us that the term should be used after obtaining the primary end point, the 1-year angiographic patency rate and its confidence interval.

Regarding your first question, graft patency was graded in the manner described by FitzGibbon and his colleagues. Grades A and $\mathrm{B}$ were treated as patent, and grade $\mathrm{O}$, anastomosis, which included stenosis of $\geq 75 \%$ of the vessel diameter or a totally occluded graft, was treated as occluded. However, we did not find any graft with stenosis of $\geq 75 \%$ during the study period.

Dr Buxton. The FitzGibbon classification, A is completely patent, $\mathrm{B}$ is a stenosis $>50 \%$ and $\mathrm{O}$ is an occlusion. So there is a slight difference, but basically you have a composite end point of occlusion and $>75 \%$ stenosis, which is acceptable.

The second question I have is, how do the authors arrive at the noninferiority margin of $-8 \%$ for the saphenous vein versus the right internal thoracic artery at the 1-year follow-up?

Dr Hwang. You mean the inferiority margin of $-8 \%$ ?

Dr Buxton. Yes. The margin is quite high for a trial that you designated the end point as being 12 months.

Dr Hwang. Inferiority margin is not an exact percentage that we expect to obtain; it is the lowest margin of confidence interval. The saphenous vein patency rates in other previous studies, including randomized and nonrandomized studies, were those of the saphenous vein, which was used as an aortocoronary bypass after 
harvest using conventional technique. Our study is different from those. We harvest the saphenous vein with minimal manipulation, avoid the intraluminal dilatation, and use it as a Y-composite graft. We expect a 1-year patency rate of the saphenous vein to be $93 \%$. We assume that a $93 \%$ patency rate with a confidence interval from 87 to 99 , which is $\pm 6 \%$, is acceptable to demonstrate noninferiority of the saphenous vein, compared with the right internal thoracic artery with a patency rate of $95 \%$. There were no references to decide inferiority margin.

Dr Buxton. The only point I am making is that some of the older observational data suggest high failure rates of saphenous vein grafts whereas the current, randomized, controlled trials that we have of Hayward, Goldman, and Collins suggest that, in fact, the current failure rate of saphenous vein grafts in this setting has improved or is better than historical data. In other words, the results of saphenous vein grafting in this setting has lower rates and therefore it is going to make it more difficult for you to achieve your end point at 12 months.

And the third question is, if this noninferiority has not been reached or not demonstrated at 1 year, what plans do you have to extend the trial to perhaps 5 years, if required?

Dr Hwang. We believe that we will get noninferiority results at 1 year. Regardless of the 1 -year result of this randomized trial, we are planning to extend the study duration and we are going to perform follow-up angiograms at 5 years after surgery.

Dr Buxton. Thank you very much and I look forward to hearing the late results.

Dr Robert A. Dion (Genk, Belgium). I just want to make a comment about the technique. You insist on the fact that $36 \%$ of your right mammary artery grafts were too short to perform a full revascularization. When I have to go very far on the inferior wall of the left ventricle with a free right internal mammary artery, I do the $\mathrm{Y}$ anastomosis last, because it allows me to use, optimally and sequentially, the right mammary artery and to decide at the end where I perform the anastomosis on the left mammary artery and which orientation I choose. During the past 10 years I very rarely needed to use a third graft, even in dilated ventricles. It is indeed technically easier to perform the $\mathrm{Y}$ anastomosis at first, but I think you win efficacy in using the length of the right mammary artery if you do it last. Thank you.

Dr Hwang. Thank you, Dr Dion. I remember that you did have the same comment to my presentation at the Society of Thoracic Surgeons meeting last year. We always perform the $Y$ anastomosis before committing distal anastomoses. By performing the Y Anastomosis first, it is possible to perfuse the coronary arteries after each distal anastomosis during off-pump coronary revascularization. We frequently observe that hemodynamic instabilities become stable after each anastomosis, especially while displacing the heart and grafting the lateral or posterior wall vessels. In addition, the average length of the harvested, skeletonized right ITA was approximately $15 \mathrm{~cm}$ and it was not always enough to revascularize the lateral and posterior-inferior coronary arteries completely in the dilated ventricle.

Dr Guo-Wei He (Tianjin, China). This is a very nice study, particularly because it is a randomized study. My question, actually, is very similar to Professor Brian Buxton's third question. You have to look at the long-term results for re-angiogram. You never answered that. I would like to make a comment on that.
The early occlusion of the graft is largely a result of technical problems, but the long-term patency and the occlusion rate for the long term largely depends on the biological characteristics of the graft.

Now, 10, 15 years ago we did a series of studies looking at the endothelial function of our grafts, including arterial and saphenous vein grafts, and we have found that the endothelium of the arterial graft, including the internal mammary artery and the radial artery and the gastroepiploic artery, all these arterial grafts release more nitric oxide as well as endothelium-derived hyperpolarizing factor than the saphenous veins. That will play a major role in the long term, beyond 5 or 10 years, as far as the occlusion rates or patency rates are concerned.

So my comment is you really cannot make a conclusion for the early 1-year angiogram to say the right mammary or left mammary artery patency rates are the same as the saphenous vein. So my comment is really we have to look at the long-term patency.

Dr Hwang. Thank you for your comment. I totally agree with you.

Dr David Glineur (Brussels, Belgium). Last year we published in the Journal of Thoracic and Cardiovascular Surgery a study on fractional flow reserve measurements with this configuration. We concluded that this configuration works perfectly, but we also found that if you graft a not very stenosed left anterior descending coronary artery, you could have a steal phenomenon in the vein group. Have you seen this phenomenon at the angio control at 1 day? Do you think it could be a problem for such a configuration?

Dr Hwang. Thank you for your question. We did not observe any flow steal phenomenon on early postoperative angiograms. Instead, we observed a few patients who showed bidirectional competition (early washout of grafted coronary artery on graft angiogram and retrograde filling of graft on native coronary angiogram) of distal left ITA grafted for moderately stenosed coronary arteries. We have to follow up with those patients to look at the fate of the Y-composite graft.

Dr Zhandong Zhou (Syracuse, NY). I have got a quick question. I am just wondering if you see any difference between a vein graft connected to the left ITA versus a vein graft that connects to the aorta? And second, this was definitely not a blind study, so do people take a better vein graft for the part that connects to the mammary artery instead of compared with the vein graft connected to the aorta?

Dr Hwang. The theoretical advantages of using the saphenous vein as a composite graft based on the internal thoracic artery are, first, the saphenous vein is not exposed to direct pressure and circulatory stress from the ascending aorta and, second, the saphenous vein is exposed continuously to nitric oxide produced from the in situ left ITA, which may reduce the risk of atherosclerotic disease.

Dr Zhou. My question is do you see any difference in terms of patency rate compared with a vein graft connected to the left ITA versus a vein graft to the aorta? Is there any difference in 1 year?

Dr Hwang. You mean patency rate?

Dr Zhou. Yes.

Dr Hwang. In our previous study, the 1-year patency rate of saphenous vein used in an aortocoronary fashion was $<80 \%$. In contrast, we recently published in the Annals of Thoracic Surgery that 
the patency rate of saphenous vein composite graft was $92 \%$ at 1 year.

Dr Zhou. Is that the same group of patients or a different group of patients? So they are not comparable, right?

Dr Hwang. No, they are not comparable. It is a limitation of retrospective studies.

Dr Zhou. It is in the same group?

Dr Hwang. No, they are not the same groups. We have changed our strategy in 2006; most aortocoronary saphenous bypasses were performed before 2006, and most saphenous vein composite grafts were constructed since 2006 .
Dr Zhou. But do you see any difference between the second graft and the third graft in your same group, because the third graft was a vein graft, right?

Dr Hwang. I am afraid that you misunderstand our third vein graft being anastomosed to the aorta. The third graft was connected to the left ITA or to the second graft as an I shape instead of to the aorta. In our previous retrospective study, we compared the patency rate of the second arterial composite and third vein composite grafts. There were no differences in patency rates between the second and third composite grafts. 